\title{
Dielectric Behavior of Some Vinyl Polymers/Montmorillonite Nanocomposites on the Way to Apply Them as Semiconducting Materials
}

\author{
Amal Amin ${ }^{1}$, Eman H. Ahmed ${ }^{1}$, Magdy W. Sabaa ${ }^{1}$, Magdy M. H. Ayoub ${ }^{1}$, Inas K. Battisha ${ }^{2}$ \\ ${ }^{1}$ Polymers and Pigments Department, National Research Center (NRC), Giza, Egypt \\ ${ }^{2}$ Solid State Physics Department, National Research Center (NRC), Giza, Egypt \\ Email: aamin_07@yahoo.com, aamin_2011@yahoo.com
}

Received May 5, 2013; revised May 29, 2013; accepted June 10, 2013

Copyright (C) 2013 Amal Amin et al. This is an open access article distributed under the Creative Commons Attribution License, which permits unrestricted use, distribution, and reproduction in any medium, provided the original work is properly cited.

\begin{abstract}
Some vinyl polymers/montmorillonite nanocomposites were prepared via in-situ-atom transfer radical polymerization (ATRP) in presence of clay. Methyl methacrylate, styrene and n-butyl methacrylate were involved in the formation of such polymeric nanocomposites. Their dielectric properties were extensively studied to invest them in the a.c. power applications. Several dielectric parameters such as dielectric constant loss $\left(\varepsilon^{\prime \prime}\right)$ and a.c. conductivity $(\sigma)$ were measured at both different frequencies $(0.1 \mathrm{~Hz}$ to $100 \mathrm{KHz})$ and temperature ranged from $\left(20^{\circ} \mathrm{C}\right.$ to $\left.90^{\circ} \mathrm{C}\right)$. From the dielectric results, it was realized that the dielectric a.c. conductivity was enhanced by increasing the temperature for the four prepared polymer nanocomposites.
\end{abstract}

Keywords: Nanocomposites; Atom Transfer Radical Polymerization; Insulation; Dielectric Measurements; Intercalation; Polarization

\section{Introduction}

At the last decades, polymers/clay nanocomposites (PCNs) became an interesting area of research where PCNs have evoked an intense industrial and academic research, due to their outstanding mechanical, thermal, chemical and electrical properties over the pure polymers [1]. Several kinds of nanofillers were used such as layered silicates which include montmorillonite as the widely used nanoclay $[2,3]$. Organic polymers, loaded with small amounts of montmorillonite (MMT) clay produce polymer-clay nanocomposites (PCNs) having a good resemblance in dielectric properties with respect to their structural properties [4]. Generally, the research work on novel polymeric materials in the field of power engineering and high voltage technology is of great significance both nationally and internationally due to the increasing demands of more cost effective and environmentally better materials for high voltage equipment [5]. Traditionally, additive agents and fillers are often used for improving dielectric and mechanical properties of materials [6]. Nowadays, polymeric nanocomposite materials are attracting attention of many researchers in the field of dielectric [7] where polymeric nanocomposites are thought to be the state of the art of dielectric materials with improved dielectric performance [8]. Polymeric semiconducting materials are widely applied to power apparatuses and cables [9]. Therefore, recent preliminary work has been already done to investigate the dielectric performance of polymeric nanocomposite materials regarding the reduction of space charge, variation of conductivity and increase of electric strength where these studies were carried out in case of various polymeric materials, doped with nanofillers [10-12]. Generally, three methods are commonly used for the synthesis of PCNs including in-situ polymerization [13], solvent intercalation [14] and polymer melt intercalation [15]. For in-situ technique, free radical polymerization is likely the most important process [16]. However, conventional free radical polymerization methods lack the control due to chain transfer and termination reactions. Therefore, living controlled polymerization techniques (LCR) appeared as the vital alternative including nitroxide mediated polymerization (NMP) [17], reversible addition fragmentation process (RAFT) [18] and metal mediated atom transfer radical polymerization (ATRP) [19]. ATRP appeared as the most attractive living controlled polymerization tech- 
niques tolerant to various monomers, solvents, temperatures and catalytic systems. The aim of the current work was to prepare some vinyl polymeric/montmorillonite clay nanocomposites via in-situ-atom transfer radical polymerization where their dielectric behavior was successively studied by measuring different related parameters such as dielectric constant $\left(\varepsilon^{\prime}\right)$, dielectric constant loss $\left(\varepsilon^{\prime \prime}\right)$ and a.c. conductivity $(\sigma)$ [20-22].

\section{Experimental Section}

\subsection{Materials}

Montmorillonite $(\mathrm{CEC}=88 \mathrm{meq} / 100 \mathrm{~g})$ was received from Sigma-Aldrich chemical company (USA). Other chemicals-otherwise mentioned were used as received from Sigma-Aldrich without further purification. The monomers such as styrene (St), methyl methacrylate (MMA), and n-butyl methacrylate (n-BuMA) were purified by filtration through an activated basic alumina column and then stored under argon in the fridge.

\subsection{Characterization}

Gel permeation Chromatography (GPC) was used to determine number-average molecular weight $\left(\overline{\mathrm{M}}_{\mathrm{nGPC}}\right)$ and polydispersity $\left(\bar{M}_{w} / \bar{M}_{n}\right)$ of the polymers by using Agilent-1100 GPC-technologies-Germany. The refractive index detector was G-1362 A with $100-10^{4}-10^{5} \mathrm{~A}^{\circ}$, using polystyrene (PS) as a standard and tetrahydrofuran (THF) as the eluent. The structures of the formed polymers were determined via proton nuclear magnetic resonance spectrometry ( $\left.{ }^{1} \mathrm{H}-\mathrm{NMR}\right)$ which was carried out with Jeol-ECA $500 \mathrm{MHz}$, using tetramethylsilane (TMS) as internal standard and $\mathrm{CDCl}_{3}$ as the main solvent. $\mathrm{X}$ ray Diffraction (XRD) measurements were carried out by using Phillips X Pert X-ray generator with $\mathrm{Cu} \mathrm{K} \alpha$ radiation at $40 \mathrm{kV}$. Dynamic mechanical thermal analyses (DMTA) were carried out with a diffractometer (type PW 1390) with employing Ni-filtered CuK. A typical sample weight was about $8-10 \mathrm{mg}$ and the analyses were performed at a heating rate of $10^{\circ} \mathrm{C} / \mathrm{min}$ from 50 to $600^{\circ} \mathrm{C}$ under Helium atmosphere. Transmission electron microscopy (TEM) was used to determine the morphology of the formed polymers/clay nanocomposites by using transmission electron microscopy (TEM-JEOL JX 1230) with micro-analyzer electron probe and magnification up to $600 \mathrm{kx}$, giving a resolution down to $0.2 \mathrm{~nm}$. The measurements were performed at an accelerating voltage of $100 \mathrm{kV}$. The dielectric measurements were performed using Computerized LRC-bridge (Hioki model $3531 \mathrm{zHi}$ Tester). The dielectric constant $\varepsilon^{\prime}$ for the investigated samples was studied at both different temperatures and frequencies ranging from $\left(20^{\circ} \mathrm{C}\right.$ to $\left.90^{\circ} \mathrm{C}\right)$ and $(0.1 \mathrm{~Hz}$ up to $100 \mathrm{KHz})$. The samples used in the dielectric measurements were in disc form, having 10 $\mathrm{mm}$ in diameter and $3 \mathrm{~mm}$ in thickness, pressed using a pressure of 10 ton at room temperature. Then, silver paste was coated to form electrodes on both sides of the sintered ceramic specimens in order to ensure good contacting. The electric measurements were carried out by inserting the sample between two parallel plate conductors forming cell capacitor. Then, the whole arrangement was placed in non-inductive furnace for heating the samples with constant rate. The relative dielectric permittivity was calculated using the relations:

$$
\begin{aligned}
& \varepsilon^{\prime}=\mathrm{Cd} / \varepsilon_{0} A \\
& \varepsilon^{\prime \prime}=\varepsilon^{\prime} \tan \delta
\end{aligned}
$$

where, $\varepsilon^{\prime}$ is the permittivity, $\varepsilon^{\prime \prime}$ is the dielectric loss and $\tan \delta$ is the loss tangent and $A$ is the area of the electrode. The a.c. resistivity of the prepared samples was estimated from the dielectric parameters. As long as the pure charge transport mechanism is the major contributor to the loss mechanism, the resistivity $(\rho)$ can be calculated using the following relation:

$$
(\rho)=1 /\left(\mathrm{w} \varepsilon_{0} \varepsilon^{\prime} \tan \delta\right) \Omega C \mathrm{~m}
$$

where $\omega=2 \pi f, \omega$ is the angular frequency and $f$ is the frequency of the applied electric field in Hertz.

$$
\sigma=2 \pi f d C \tan \delta / \mathrm{A}
$$

where $\sigma$ is the a.c. conductivity, $f$ is the operating frequency, $d$ is the thickness of the dielectrics, $\tan \delta$ is the dielectric loss, $C$ is the capacitance and $A$ is the area of the electrode.

\subsection{General Polymerization Procedure}

\subsubsection{Organic Modification of Clay with Cationic Surfactant (CTAB) [23]}

The montmorillonite clay (MMT, $20 \mathrm{gm}$ ) was dispersed in $500 \mathrm{ml}$ distilled water containing certain amount of cationic surfactant, as cetyltrimethyl ammonium bromide (CTAB) (6 gm, $0.0165 \mathrm{~mol})$ at room temperature. The temperature was increased to $80^{\circ} \mathrm{C}$ with vigorous stirring for $6-8 \mathrm{~h}$. The clay was separated by filtration and washed several times with distilled water where the filtrate was tested with $\mathrm{AgNO}_{3}$ solution (1 gm $\mathrm{AgNO}_{3}$ in $100 \mathrm{ml}$ distilled $\mathrm{H}_{2} \mathrm{O}$ ) to obtain the modified clay without CTAB residuals. The resulting modified clay with CTAB (MMT-CTAB) was dried under vacuum at $60^{\circ} \mathrm{C}$ for $24 \mathrm{~h}$. MMT-CTAB was grinded and characterized via XRD and TEM.

\subsubsection{Preparation of the MMA or St Homopolymers/ Montmorillonite Nanocomposites [24]}

MMT-CTAB $(0.15 \mathrm{~g}, 4 \%$ filler $)$ was placed in a test tube, then bipyridine (bpy) $\left(0.15 \mathrm{~g}, 4.9 \times 10^{-4} \mathrm{~mol}\right)$ and $\mathrm{CuBr}$ (I) 
$\left(0.07 \mathrm{~g}, 4.9 \times 10^{-4} \mathrm{~mol}\right)$ were added. The tube was closed and purged with argon for 15 minutes. $5.2 \mathrm{ml}$ of MMA or $5.6 \mathrm{ml}$ of St $\left(4.9 \times 10^{-2} \mathrm{~mol}\right)$ were successively injected into the reaction mixture under argon atmosphere. The tube was immersed in an oil bath with continuous stirring at $90^{\circ} \mathrm{C}$. The reaction mixture was left for 10 minutes, then, $1 \mathrm{ml}\left(4.9 \times 10^{-4} \mathrm{~mol}\right)$ of ethyl-2-bromoisobutyrate was added to the reaction mixture as a sacrificial initiator. After $6 \mathrm{~h}$, the vial was opened and the polymerization was terminated by adding THF to the reaction mixture. The polymers/clay nanocomposites were washed with aqueous solution of disodium salt ethylene-diamine-tetraacetic acid (EDTA-disodium salt) to remove the catalysts and dried in vacuum at $40^{\circ} \mathrm{C}$. For GPC measurements, the free polymer was separated by precipitation of THF solution in n-hexane, then filtration, re-dissolving it in THF and passing through alumina column to get the free polymer.

\subsubsection{Preparation of Co- and Ter-}

\section{Polymers/Montmorillonite Nanocomposites}

The co- and ter-polymerization experiments were carried out as previously described in case of homo-polymers but in different amounts as:

\subsubsection{In Case of Copolymers}

$0.3 \mathrm{~g}$ of MMT-CTAB, $0.306 \mathrm{~g}\left(9.8 \times 10^{-4} \mathrm{~mol}\right)$ of bpy and $0.14 \mathrm{~g}\left(4.9 \times 10^{-4} \mathrm{~mol}\right)$ of $\mathrm{CuBr}(\mathrm{I})$ were added. 5.6 $\mathrm{ml}\left(4.9 \times 10^{-2} \mathrm{~mol}\right)$ of St were added under argon atmosphere with continuous stirring. After $4 \mathrm{~h}$, the vacuum was applied to the reaction mixture to remove the remaining of the first monomer, then, $5.2 \mathrm{ml}\left(4.9 \times 10^{-2}\right.$ mol) of MMA were added and the reaction was left for additional $20 \mathrm{~h}$.

\subsubsection{In Case of Ter Polymerization}

$0.45 \mathrm{~g}$ of MMT-CTAB, $0.45 \mathrm{~g}\left(9.8 \times 10^{-4} \mathrm{~mol}\right)$ of bpy and $0.21 \mathrm{~g}\left(4.9 \times 10^{-4} \mathrm{~mol}\right)$ of $\mathrm{CuBr}(\mathrm{I})$ were added. Then, the vessel was closed for $30 \mathrm{~min}$. Then, the first and second monomers were sequentially added as previously described. St and MMA were added as in case of copolymerization. $7.7 \mathrm{ml}$ of $\mathrm{n}$-BuMA $\left(4.9 \times 10^{-2} \mathrm{~mol}\right)$ were added after $24 \mathrm{~h}$. The reaction was left for additional $24 \mathrm{~h}$ and terminated by adding THF as previously described.

\section{Results and Discussion}

Several polymers/MMT nanocomposites were prepared via in-situ-atom transfer radical polymerization (ATRP) of some vinyl monomers. On that way, MMT was modified with CTAB cationic surfactant where the basal spacing (d) increased from $1.210 \mathrm{~nm}$ at 2 theta of 7.5 for MMT to $1.837 \mathrm{~nm}$ at 2 theta value of 5 for MMT-CTAB. That extension in the interlayer distance between the clay platelets was referred to the intercalation of the CTAB molecules between the clay layers which caused widening of the interlayer distance. MMA and St/MMT nanocomposites were prepared via in-situ ATRP in presence of MMT-CTAB. Block copolymer/MMT nanocomposite was obtained by in-situ ATRP of St and applying vacuum to get rid of the monomer residuals, then adding MMA as the second monomer. In case of block terpolymer, n-BuMA was added as the third monomer after successive additions of St and MMA, respectively and by removing the excess of each monomer by vacuum before proceeding in further new polymerization step. The resulting polymers/MMT nanocomposites such as PMMA, PSt, PSt-b-MMA and PSt-b-MMA-b-n-BuMA/MMT were characterized via XRD, TGA, DSC and TEM. As shown in Figure 1, XRD indicated d values of $1.174 \mathrm{~nm}$ and $1.019 \mathrm{~nm}$ for PMMA/MMT and PSt-b-PMMA/MMT at 2 theta values of 7.7 and 8.7, respectively, with lower intensity than recorded for MMT-CTAB. The values of basal spacing $d$ for both PSt/MMT and PSt-b-PMMA-bP-n-BuMA/MMT were 8.251 and $1.894 \mathrm{~nm}$ at 2 theta values of 10.7 and 5.7, respectively. The formed polymers/MMT nanocomposites were characterized via TGA where as shown in Figure 2, PMMA lost about 88\% from its initial mass where the degradation started at $170^{\circ} \mathrm{C}$ with slight weight loss $(2.0 \%)$ till $310^{\circ} \mathrm{C}$. Then, it lost $85.55 \%$ of its weight from 310 up to $455^{\circ} \mathrm{C}$ where the sample completely decomposed at $600^{\circ} \mathrm{C}$. Pst sample lost about $42.2 \%$ from its initial mass where it started to decompose at $120^{\circ} \mathrm{C}$ and it lost $2.11 \%$ of its weight till $150^{\circ} \mathrm{C}$ then it lost $12.78 \%$ up to $260^{\circ} \mathrm{C}$ followed by weight loss of $17.97 \%$ up to $410^{\circ} \mathrm{C}$ where the complete decomposition occurred at $600^{\circ} \mathrm{C}$. On the other hand, in case of PSt-b-PMMA, the sample stayed unaffected till $200^{\circ} \mathrm{C}$ where it began to lose about $8 \%$ of its weight up to $340^{\circ} \mathrm{C}$, and then gradual decomposition happened where it lost $45.11 \%$ up to $440^{\circ} \mathrm{C}$ and finally complete degradation was recorded at $600^{\circ} \mathrm{C}$. Generally, it seemed that PSt-b-PMMA lost about 54\% from its initial mass. In case of PSt-b-PMMA-b-P-n-BuMA, it lost about $73.94 \%$ from its initial mass where it started to decompose at $30^{\circ} \mathrm{C}$ up to $130^{\circ} \mathrm{C}$ with a weight loss $14.6 \%$, and then the sample gradually degraded up to $415^{\circ} \mathrm{C}$ with weight loss of $47.94 \%$ and $11.4 \%$ at two stages but the sample completely degraded at $600^{\circ} \mathrm{C}$.

DSC measurements indicated $\mathrm{T}_{\mathrm{g}}$ values of $90^{\circ} \mathrm{C}$, $117^{\circ} \mathrm{C}, 156^{\circ} \mathrm{C}$ and $180^{\circ} \mathrm{C}$ for PMMA, PSt, PSt-b-PMMA and PSt-b-PMMA-b-P-n-BuMA polymers inside their nanocomposites with MMT. Some of the prepared nanocomposites were characterized by TEM as shown in Figure 3. TEM showed that the stacks of the intercalated clay platelets are embedded in the polymer matrices showing good distribution of the MMT particles within the polymer matrices. The structure of the resulting polymers was confirmed by ${ }^{1} \mathrm{H}-\mathrm{NMR}$ [25]. ${ }^{1} \mathrm{H}-\mathrm{NMR}$ of 

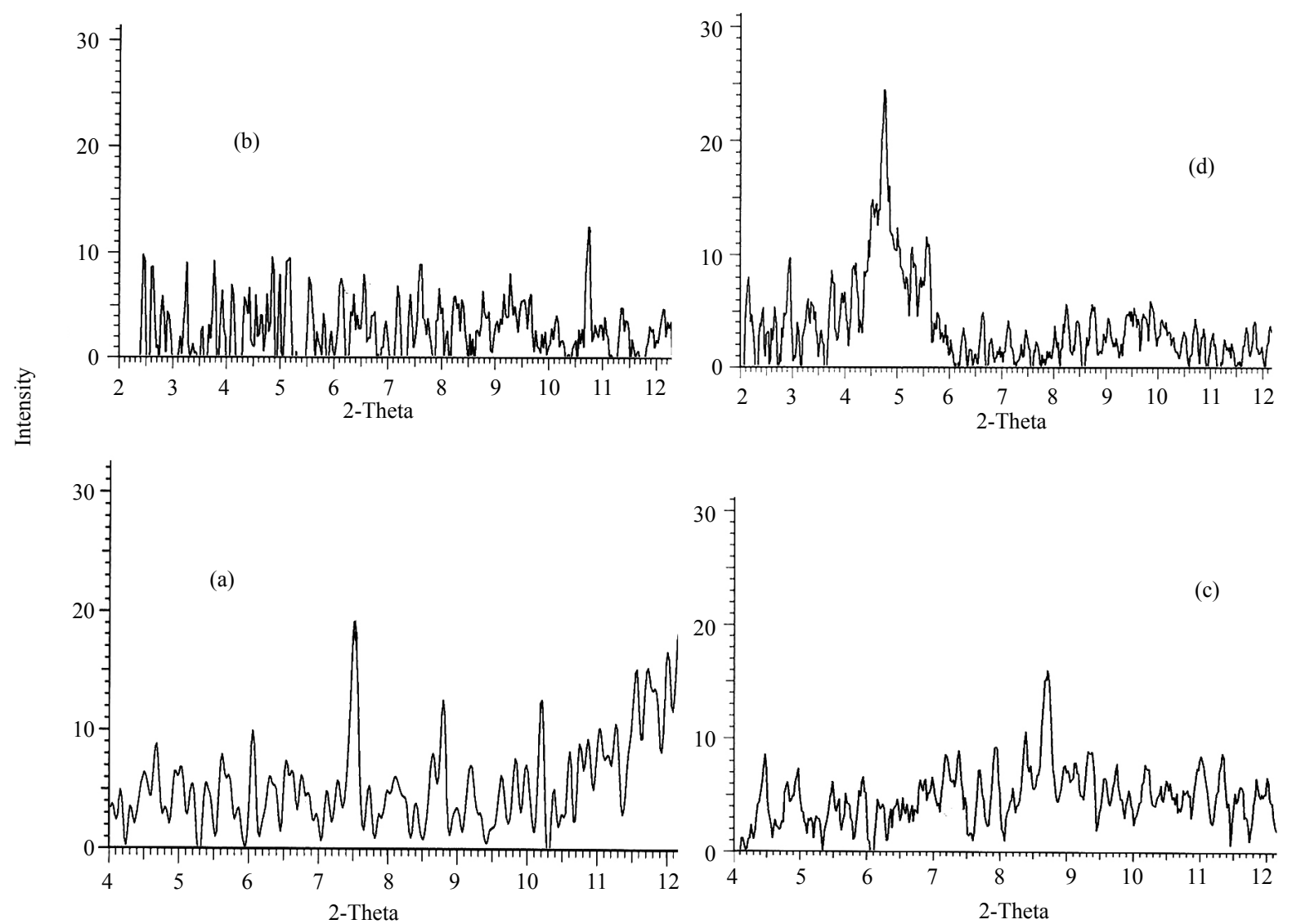

Figure 1. XRD of (a) PMMA/MMT, (b) PSt/MMT, (c) Pst-b-PMMA/MMT, (d) PSt-b-PMMA-b-P-n-BuMA/MMT nanocomposites.

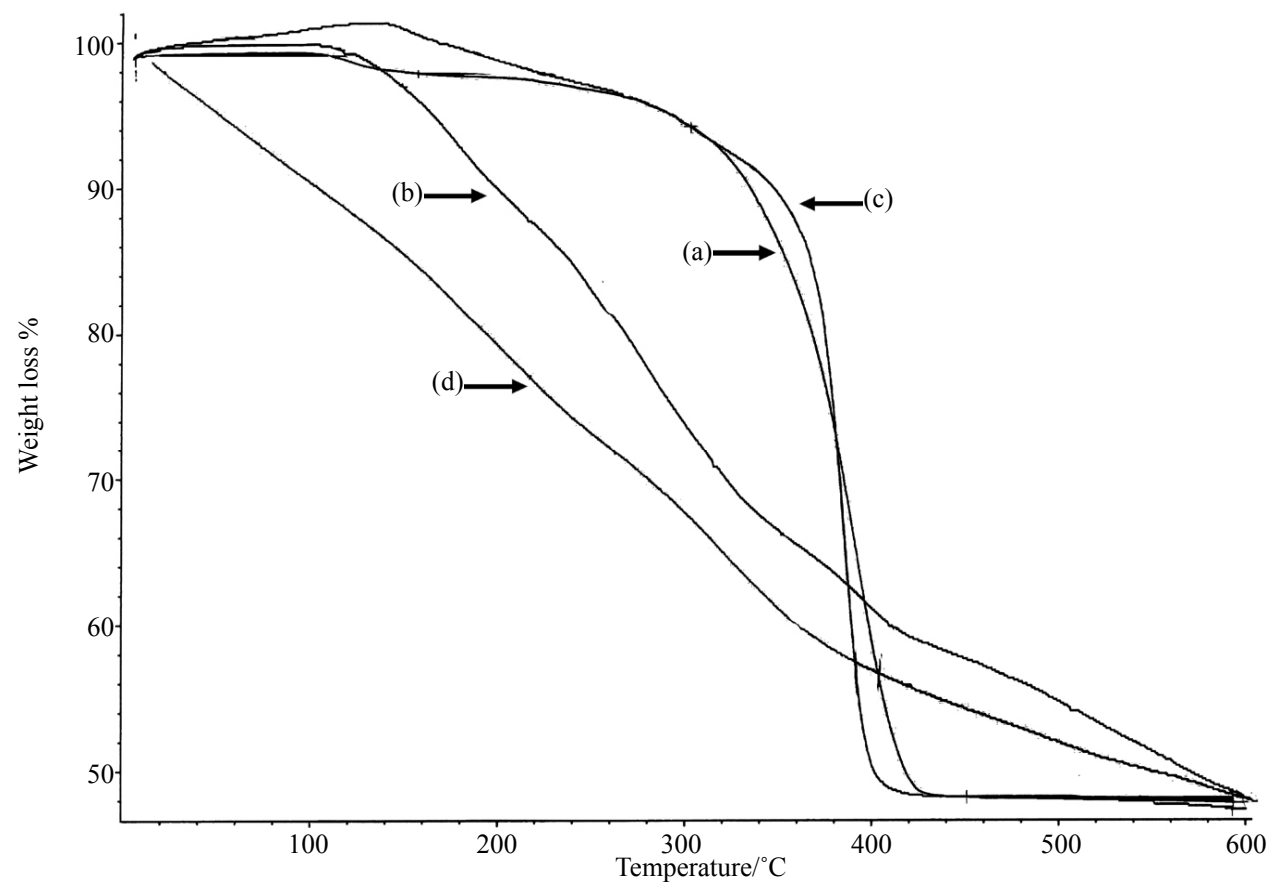

Figure 2. TGA of (a) PMMA/MMT; (b) PSt/MMT; (c) Pst-b-PMMA/MMT; (d) PSt-b-PMMA-b-P-nBuMA/MMT nanocomposites. 


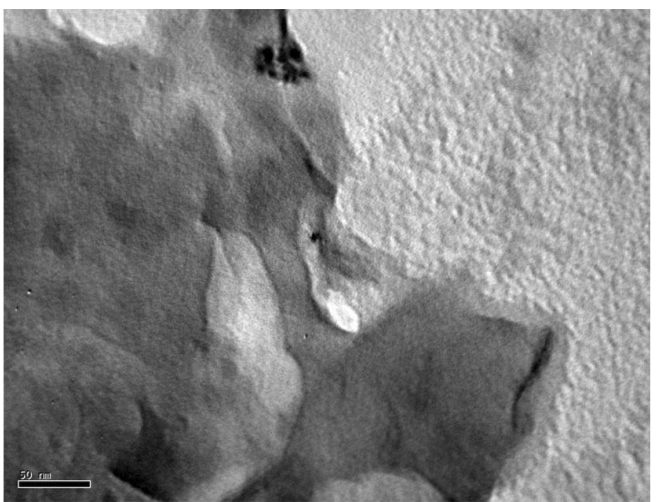

(a)

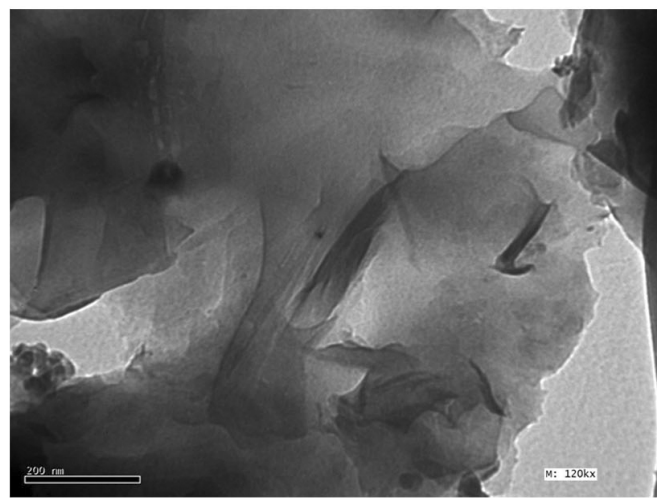

(c)

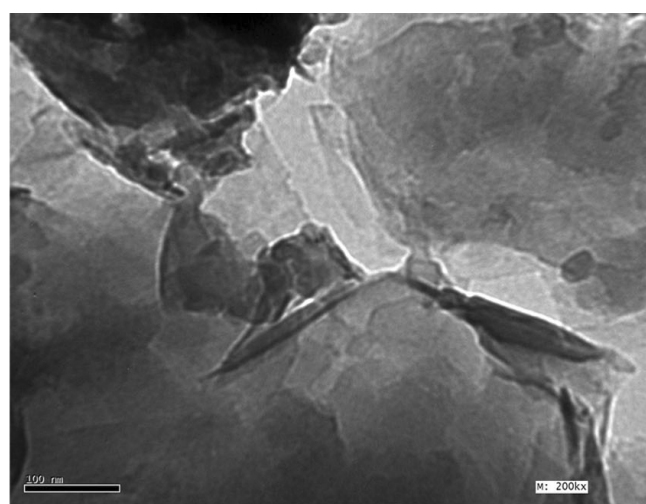

(b)

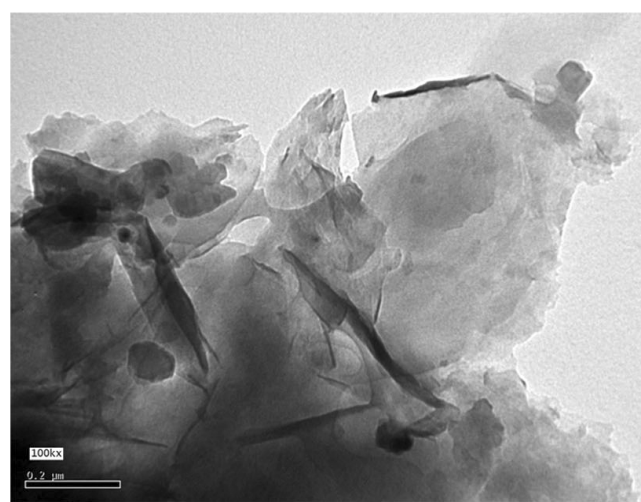

(d)

Figure 3. TEM of (a) PMMA/MMT; (b) PSt/MMT; (c) Pst-b-PMMA/MMT; (d) PSt-b-PMMA-b-P-nBuMA/MMT nanocomposites.

MMA polymer, indicated the appearance of characteristic bands at chemical shifts $(\delta, \mathrm{ppm})$ at $(0.8-1.3)$ for $\left(\mathrm{CH}_{3} \mathrm{CH}_{2}, \mathrm{C}-\mathrm{CH}_{3}\right), 1.5-1.9$ for $\left(\mathrm{CH}_{3} \mathrm{CH}_{2}\right)$ and at 3.5 for $\left(\mathrm{OCH}_{3}\right)$. However, for St polymer, dense bands appeared in high intensity at $\delta=6.5-7.5$ which were referred to the phenyl groups inside the skeleton of the polymer. On the other hand, (Br-CH-ph) appeared at $\delta=4 \mathrm{ppm}$. In case of PSt-b-PMMA copolymer, typical bands for both MMA and St units were observed. Similarly, in case of PSt-b-PMMA-b-P-n-BuMA, characteristic bands for St. and MMA were noticed in addition to several bands at 2 2.9 which were attributed to several $\left(\mathrm{CH}_{2}\right)$ groups inside the terpolymer skeleton in occasion of the presence of n-BuMA moiety.

\section{Dielectric Measurements of Polymers/Clay Nanocomposites [26,27]}

The dielectric constant loss $\varepsilon^{\prime \prime}$ and a.c. conductivity $(\sigma)$ were studied in the temperature range $\left(20^{\circ} \mathrm{C}-90^{\circ} \mathrm{C}\right)$ and frequency range $(0.1 \mathrm{~Hz}$ up to $100 \mathrm{KHz})$ for all polymers/clay nanocomposites samples. Figures 4(a)-(d) shows the variation of the dielectric loss $\varepsilon^{\prime \prime}$ of poly (a, PMMA/ MMT), (b, PSt/MMT), (c, PSt-b-PMMA/MMT) and (d, PSt-b-PMMA-b-P-n-BuMA/MMT) nanocomposites sam- ples as a function of frequency at various tempera- tures. From these graphs, it was noticed that the dielectric loss decreased by increasing the frequency for all investigated samples. This behavior for all polymers/clay nanocomposites prepared samples can be described by the Debye dispersion relation [28],

$$
\varepsilon^{\prime \prime}=\omega \tau\left[\left(\grave{\mathrm{e}}_{s}-\mathrm{e}_{\infty} / 1+\omega^{2} \tau^{2}\right)\right],
$$

where the interfacial polarization dominates [29] at relatively low frequency range which competes the mentioned normal behavior (the rise of $\varepsilon$ " with increasing frequency). This leads to diminish the low frequency behavior. Tareev et al., [30] reported that, as the frequency increases, many types of losses get to be reduced because the field frequency begins to exceed their characteristic natural frequency. This is ascribed to the initial high value of dielectric parameters for polar materials, but as the frequency of the field is raised, the value begins to drop which may be due to the fact that the dipoles not being able to follow the field variation at higher frequencies and also due to the polarization effects.

Figures 5(a)-(d) show the dependence of a.c. conductivity on the frequency at different temperatures for (a, PMMA/MMT), (b, PSt/MMT), (c, PSt-b-PMMA/MMT) and (d, PSt-b-PMMA-b-P-n-BuMA/MMT) nanocomposites. The a.c. conductivity behavior of all prepared sam- 

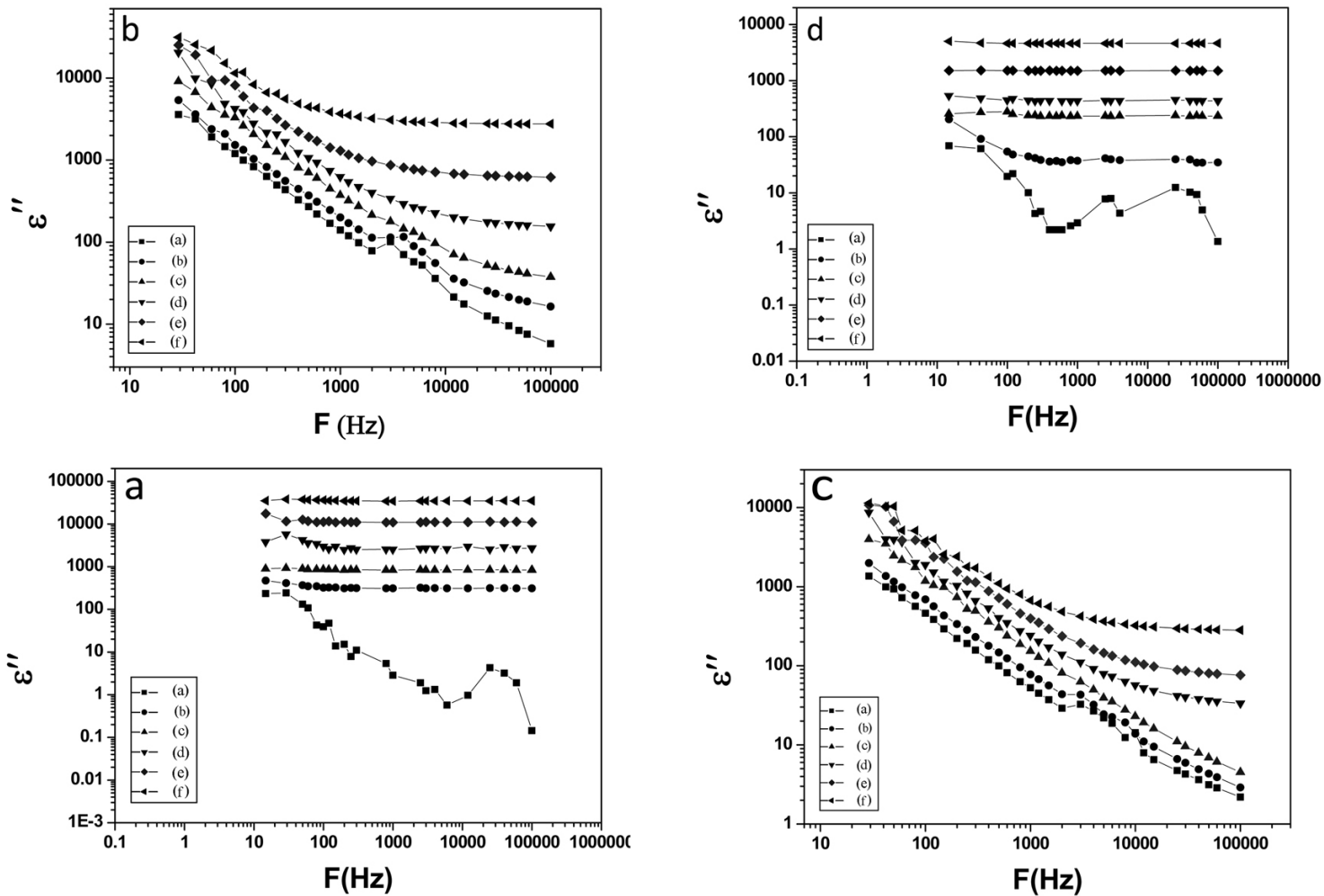

Figure 4. The dielectric constant loss $\varepsilon^{\prime \prime}$ as a function of frequency, (a) PMMA/MMT, (b) PSt/MMT, (c) Pst-b-PMMA/MMT, (d) Pst-b-PMMA-b-P-n-BuMA/MMT, where $\mathrm{a}=20^{\circ} \mathrm{C}, \mathrm{b}=40^{\circ} \mathrm{C}, \mathrm{c}=60^{\circ} \mathrm{C}, \mathrm{d}=70^{\circ} \mathrm{C}, \mathrm{e}=80^{\circ} \mathrm{C}, \mathrm{f}=90^{\circ} \mathrm{C}$.
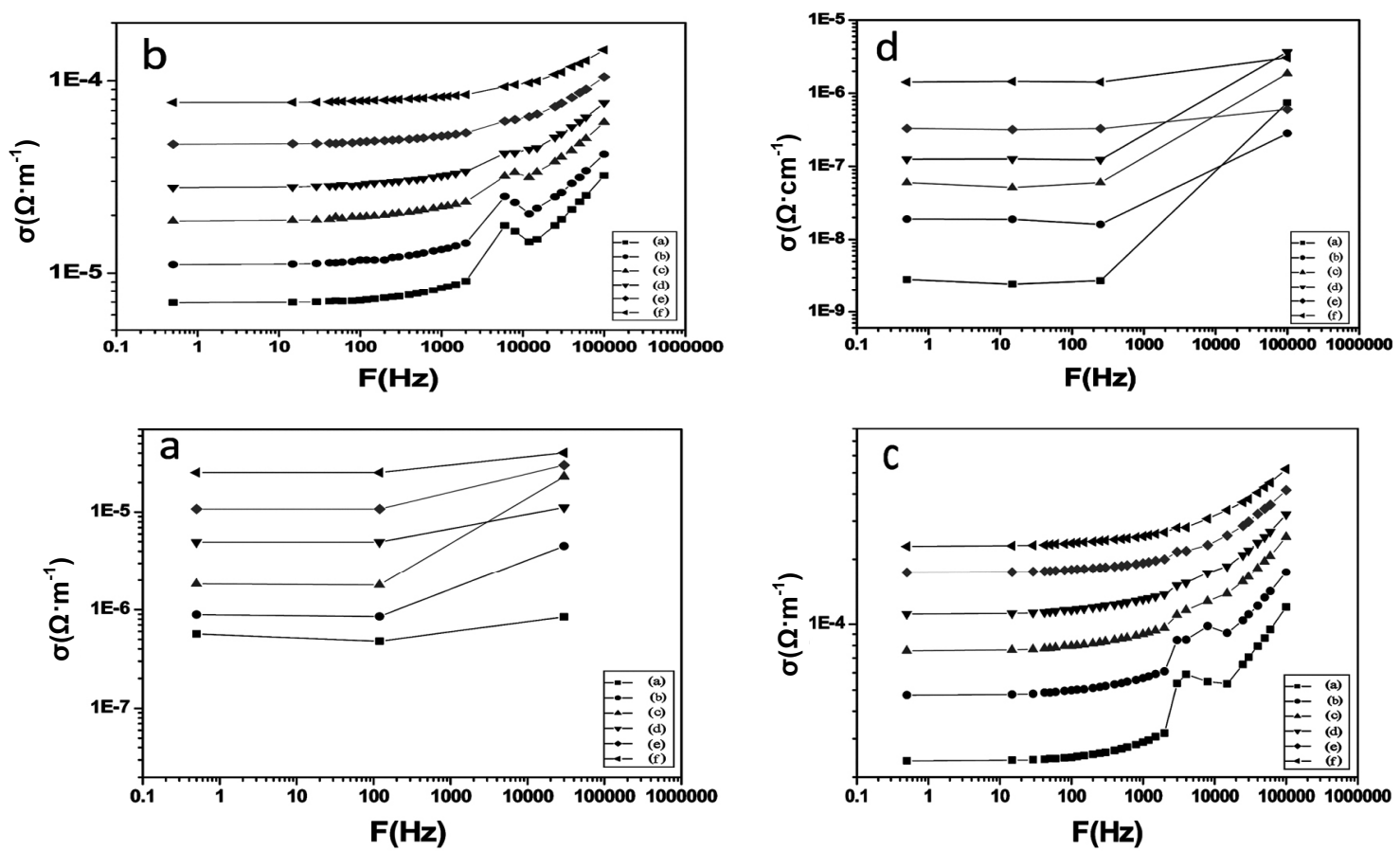

Figure 5. F as a function of a.c. conductivity $\sigma_{\text {a.c. }}$ of (a) PMMA/MMT, (b) Pst/MMT ,(c) Pst-b-PMMA/MMT, (d) Pst-bPMMA-b-P-nBuMA/MMT, where $\mathrm{a}=20^{\circ} \mathrm{C}, \mathrm{b}=40^{\circ} \mathrm{C}, \mathrm{c}=60^{\circ} \mathrm{C}, \mathrm{d}=70^{\circ} \mathrm{C}, \mathrm{e}=80^{\circ} \mathrm{C}, \mathrm{f}=90^{\circ} \mathrm{C}$.

ples was investigated at both frequency and temperature ranges from $(0.1 \mathrm{~Hz}$ up to $100 \mathrm{KHz})$ and $\left(20\right.$ up to $\left.90^{\circ} \mathrm{C}\right)$, respectively. It was found that the a.c. conductivity for all the prepared samples remarkably increased by in- 
creasing the frequency, exhibiting nearly similar behaveior. The maximum values of the a.c. conductivity of (b, PSt/MMT) and (c, PSt-b-PMMA/MMT) exhibited higher conductivities when compared with (a, PMMA/MMT) and (d, PSt-b-PMMA-b-P-n-BuMA/MMT) nanocomposites, as shown in Figures 5(b) and (c) as a result of good intercalation of PSt and PSt-b-PMMA in montmorillonite clay and tremendous increase of the mobility of charge carriers. For the four systems, the a.c. conductivities were enhanced by increasing the temperature from 20 up to $90^{\circ} \mathrm{C}$. The samples exhibited better a.c. conduction at high temperature where the intercalation of polymers within clay interlayers was advantageous to the movement of $\mathrm{Li}^{+}$ions inside these interlayers which, resulted in the increase of a.c. conductivity. The lower values of a.c. conductivities at lower temperatures were attributed to two reasons [31]; 1) a few of un-intercalated polymers remained in the grain boundary of montmorillonite clay in addition to the excessive polymer in the exterior of montmorillonite which caused decrease in the a.c. conductivity at low temperature and 2) the number of charge carriers, had high relaxation time due to higher energy barrier at lower temperature and might be less in number with low barrier at higher temperature causing an increase in the a.c. conductivity [32].

\section{Conclusion}

Vinyl polymers/montmorillonite clay nanocomposites were prepared via in-situ-atom transfer radical polymerization (ATRP). Their dielectric properties were extensively studied to invest them in the a.c. power applications. Intercalated vinyl polymers/MMT nanocomposites gave enhanced values of the dielectric parameters such as a.c. conductivity $(\sigma)$, and dielectric constant loss $\left(\varepsilon^{\prime \prime}\right)$. For the four systems, the a.c. conductivities were enhanced by increasing the temperature from $20^{\circ} \mathrm{C}$ up to $90^{\circ} \mathrm{C}$. The samples exhibited better a.c. conduction $(\sigma)$ at high temperature where increasing temperature facilitated the intercalation of polymers inside clay layers which was advantageous to $\mathrm{Li}^{+}$ions movement inside these layers which results in the increase of a.c. conductivity.

\section{REFERENCES}

[1] M. Biswas and S. S. Ray, "Recent Progress in Synthesis and Evaluation of Polymer-Montmorillonite nanocomposites," Advances in Polymer Science, Vol. 155, 2001, 167221. doi:10.1007/3-540-44473-4_3

[2] S. Pande, H. Swaruparani, M. D. Bedre, R. Bhat, R. Deshpande and A. Venkataraman, "Synthesis, Characterization and Studies of PANI-MMT Nanocomposites," Nanoscience and Nanotechnology, Vol. 2, No. 4, 2012, pp. 9098. doi:10.5923/j.nn.20120204.01

[3] W. Zhai, C. B. Park and M. Kontopoulou, "Nanosilica Addition Dramatically Improves the Cell Morphology and Expansion Ratio of Polypropylene Heterophasiccopolymer Foams Blown in Continuous Extrusion," Industrial \& Engineering Chemistry Research, Vol. 50, No. 12, 2011, pp. 7282-7289. doi:10.1021/ie102438p

[4] I. L. Hosier, A. S. Vaughan and S. G. Swingler, "On the Effects of Morphology and Molecular Composition on the Electrical Strength of Polyethylene Blends," Journal of Polymer Science Part B: Polymer Physics, Vol. 38, No. 17, 2000, pp. 2309-2322.

[5] F. Frutos, M. Acedo, M. Mudarra, J. Belana, J. Òrrit, J. A. Diego, J. C. Cañadas and J. Sellarès, "Effect of Annealing on Conductivity in XLPE Mid-Voltage Cable Insulation," Journal of Electrostatics, Vol. 65, No. 2, 2007, pp. 122131.

[6] P. Dubois and M. Alexandre, "Performant Clay/Carbon Nanotube Polymer Nanocomposites," Journal of Advanced Engineering Materials, Vol. 8, No. 3, 2006, pp. 135-221.

[7] T. Tanaka, M. Kazako and N. Fuse, "Dielectric Nanocomposites with Insulating Properties," IEEE Transactions on Dielectrics and Electrical Insulation, Vol. 12, 2005, pp. 669-681.

[8] C. C. Reddy and T. S. Ramu, "Investigation of Space Charge Distribution and Volume Resistivity of XLPE/ $\mathrm{MgO}$ Nanocomposite Material under DC Voltage Application," Transactions on Dielectrics and Electrical Insulation, Vol. 15, No. 1, 2008, pp. 310- 322.

[9] M. C. Lança, M. Fu, E. Neagu, L. A. Dissado, J. M. Mendes, A. Tzimas and S. Zadeh, "Space Charge Analysis of Electrothermally Aged XLPE Cable Insulation," Journal of Non-Crystalline Solids, Vol. 353, No. 47-51, 2007, pp. 4462-4466.

[10] M. Mukherjee, B. Mukherjee, Y. Choi, K. Sim, J. Do and S. Pyo, "Investigation of Organic n-Type Field Effect Transistor Performance on the Polymeric Gate Dielectrics," Synthetic Metals, Vol. 160, No. 5-6, 2010, pp. 504509.

[11] S. H. Sonawane, "Removal of Brilliant Green from Wastewater Using Conventional and Ultrasonically Prepared Poly(acrylic acid) Hydrogel Loaded with Kaolin Clay: A Comparative Study," Ultrasonics Sonochemistry, Vol. 20, No. 3, 2013, pp. 914-923.

[12] Y. Maekawa, T. Yamanaka, T. Kimura, Y. Murat, S. Katakai, "The Hitachi Densen," 2002.

[13] M. F. J. Solomon, Y. Bhole and A. G. Livingston, "High Flux Hydrophobic Membranes for Organic Solvent NanoFiltration (OSN) - Interfacial Polymerization, Surface Modification and Solvent Activation," Journal of Membrane Science, Vol. 434, 2013, pp. 193-203.

[14] P. S. Suchithra, L. Vazhayal, A. P. Mohamed and S. Ananthakumar, "Mesoporous Organic-Inorganic Hybrid Aerogels through Ultrasonic Assisted Sol-Gel Intercalation of Silica-PEG in Bentonite for Effective Removal of Dyes, Volatile Organic Pollutants and Petroleum Products from Aqueous Solution," Chemical Engineering Journal, Vol. 200-202, 2012, pp. 589-600. doi:10.1016/j.cej.2012.06.083

[15] Z. Chen, X. Chen, Z. Shao, Z. Yao and L. T. Biegler, "Parallel Calculation Methods for Molecular Weight Distribution of Batch Free Radical Polymerization," Compu- 
ters and Chemical Engineering, Vol. 48, 2013, pp. 175186. doi:10.1016/j.compchemeng.2012.09.002

[16] S. Sadhu and A. K. Bhowmick, "Preparation and Characterization of Styrene Butadiene Rubber Based Nanocomposites and Study of their Mechanical Properties," Advanced Engineering Materials, Vol. 6, No. 9, 2004, pp. 738-742.

[17] B. Charleux, "Review Nitroxide-Mediated Polymerization," Progress in Polymer Science, Vol. 38, No. 1, 2013, pp. 63-235. doi:10.1016/j.progpolymsci.2012.06.002

[18] A. B. Gomide, C. H. Thome, G. A. dos Santos and G. A. Ferreira, "Disrupting Membrane Raft Domains by AlkylPhospholipids," Biochimica et Biophysica Acta, Vol. 1828, No. 5, 2013, pp. 1384-1389.

[19] G. D. Fu, Z. Shang, L. Hong, E. T. Kang and K. G. Neoh, "Preparation of Cross-Linked Polystyrene Hollow Nanospheres via Surface-Initiated Atom Transfer Radical Polymerizations," Macromolecules, Vol. 38, No. 18, 2005, pp. 7867-7871. doi:10.1021/ma0509098

[20] K. Terashima, "Insulation of Cables Using Pulsed Electroacoustic Method," Transactions on Power Delivery, Vol. 13, 1998, pp. 7-16. doi:10.1109/61.660837

[21] Y. Murata, Y. Sekiguchi, Y. Inoue and M. kanaoka, Electrical Insulating Materials, Vol. 2, 2005, pp. 650-653.

[22] Y. Cao et al., "The Future of Nanodielectrics in the Electrical Power Industry," IEEE Transactions on Dielectrics and Electrical Insulation, Vol. 11, No. 5, 2004, pp. 797807.

[23] M. Xu, Y. S. Choi, Y. K. Kim, K. H. Wang and I. J. Chung, "Synthesis and Characterization of Exfoliated Poly(styrene-co-methyl methacrylate)/Clay Nanocomposites via Emulsion Polymerization with AMPS," Polymer, Vol. 44, No. 12, 2003, pp. 6387-6395.

[24] H. Datta, N. K. Singha and A. K. Bhowmick, "Beneficial
Effect of Nanoclay in Atom Transfer Radical Polymerization of Ethylacrylate: A One Pot Preparation of Tailor Made Polymer Nanocomposites," Macromolecules, Vol. 41, No. 1, 2010, pp. 50-57. doi:10.1021/ma071528s

[25] A. Amin, R. Sarkar, C. N. Moorefield and G. R. Newkome, "Synthesis of Polymer-Clay Nanocomposites of Some Vinyl Monomers by Surface Initiated Atom Transfer Radical Polymerization," Designed Monomers and Polymers. doi:10.1080/15685551.2013.771304

[26] S. Singha and M. J. Thomas, "Permittivity and Tan Delta Characteristics of Epoxy Nano Composites," IEEE Transactions on Electrical Insulation, Vol. 15, No. 1, 2008, pp. 2-11. doi:10.1109/T-DEI.2008.4446731

[27] N. M. Renukappa and G. Swaminathan, "Experimental Investigation of the Influence of Clay on Dielectric Properties of Epoxy Nanocomposites," Proceedings of the 9th International Conference on Properties and Applications of Dielectric Materials, 19-23 July 2009, Harbin, pp. 833-836.

[28] P. Debye, "Polar Molecules," Dover, New York, 1945.

[29] A. K. Jonscher, "The 'Universal' Dielectric Response," Nature, Vol. 267, No. 5613, 1977, pp. 673-679. doi: $10.1038 / 267673 \mathrm{a} 0$

[30] B. Tareev, "Physics of Dielectric Materials," Mir Publications, Moscow, 1979.

[31] W. Chen, Q. Xu and R. Z. Yuan, "Effect on Ionic Conductivity with Modification of Polymethylmethacrylate in Poly(ethylene oxide)-Layered Silicate Nanocomposites (PLSN)," Materials Science and Engineering, Vol. 77, No. 1, 2000, pp. 15-18. doi:10.1016/S0921-5107(00)00448-7

[32] I. I. Prepechko, "An Introduction to Polymer Physics," Mir Publications, Moscow, 1981. 